Research Paper

\title{
Prognostic Factors and Recurrence Patterns in T4 Gastric Cancer Patients after Curative Resection
}

\author{
Bao-Yan Zhu\#, Shu-Qiang Yuan\#, Run-Cong Nie\#, Shu-Man Li\#, Li-Rong Yang, Jin-Ling Duan, Ying-Bo \\ Chen $^{* \bowtie}$, and Xiao-Shi Zhang ${ }^{* \bowtie}$ \\ Sun Yat-sen University Cancer Center; State Key Laboratory of Oncology in South China; Collaborative Innovation Center for Cancer Medicine, Guangzhou, \\ China \\ \# These authors contributed equally to this study. \\ * These authors also contributed equally to this study. \\ $\triangle$ Corresponding author: Xiao-Shi Zhang, Tel: +86-020-87343382; E-mail: zhangxsh@sysucc.org.cn and Ying-Bo Chen, Tel: +86-020-87343625; E-mail: \\ chenyb@sysucc.org.cn. Sun Yat-sen University Cancer Center; State Key Laboratory of Oncology in South China; Collaborative Innovation Center for Cancer \\ Medicine, 651 E Dongfeng Road, Guangzhou, Guangdong, 510060, China. \\ (C) Ivyspring International Publisher. This is an open access article distributed under the terms of the Creative Commons Attribution (CC BY-NC) license \\ (https://creativecommons.org/licenses/by-nc/4.0/). See http://ivyspring.com/terms for full terms and conditions.
}

Received: 2018.08.04; Accepted: 2019.01.04; Published: 2019.01.29

\begin{abstract}
Background: To investigate prognostic factors and recurrence patterns in T4 gastric cancer (GC) patients after curative resection.

Methods: Between January 2004 and December 2014, 249 patients with T4 gastric cancer undergoing curative resection were recruited. Patient characteristics, survival, prognostic factors and recurrence patterns were analyzed.

Results: Our results showed that the median survival time (MST) for T4 gastric cancer after curative resection was 55.47 months, with 59.47 months for T4a (tumor perforating serosa) and 25.90 months for T4b (tumor invasion of the adjacent structure). Multivariate analysis indicated that age (hazard ratio $[H R], 1.86 ; P=0.006)$, location of tumor $(H R, 1.25,0.90-5.64 ; P<0.001)$ and intraoperative blood loss $(H R, 1.85 ; P=0.010)$ were independent prognostic factors for overall survival (OS). After a median follow-up of 25.87 months, a total of 109 (43.8\%) patients suffered from recurrence, and 90 patients had been observed specific recurrence sites, among which peritoneal metastasis was the most common recurrence pattern, $59.0 \%$ for T4a and $88.3 \%$ for T4b, respectively.

Conclusions: For T4 gastric cancer patients after curative resection, older age, gastric cancer of the entire stomach and more intraoperative blood loss were associated with poor OS. The recurrence rate after curative resection for $\mathrm{T} 4$ was high, and the most common recurrence pattern was peritoneal metastasis.
\end{abstract}

Key words: T4 gastric cancer; curative resection; prognosis; recurrence; survival

\section{Introduction}

Gastric cancer is the fifth most common malignant tumor in the world and the third most common cause of malignant tumor-related death [1]. Though the overall survival (OS) of gastric cancer patients has improved with the development of standardized D2 lymphadenectomy [2] and subsequent adjuvant chemotherapy in recent years [3, 4], the long-term survival rate is still unsatisfactory.
Moreover, the majority of gastric cancer patients in China were diagnosed as advanced gastric cancer (AGC) at an early visit. The overall 5-year OS for AGC patients is below $20 \%$, and it is approximately $30 \%$ for those who undergo surgery. Even after curative resection, only $30-50 \%$ of patients are still alive after 5 years [5]. Among AGC T4 gastric cancer patients, which includes tumor perforating serosa (T4a) and 
invasion of the adjacent structure (T4b), patients often suffered from recurrence and had dismal overall survival, even after R0 resection. Several studies have reported potential prognostic factors affecting the survival of $\mathrm{T} 4$ gastric cancer patients after curative resection, including lymph node metastasis, venous invasion, peritoneal washing cytology and tumor diameter[6-8]. However, the sample sizes of previous studies were small.

Recurrence is the most important factor affecting the survival of patients with GC. After curative resection for GC, recurrence patterns include local-regional recurrence, distant lymph node metastasis, hematogenous metastasis, and peritoneum implantation. According to soil and seed theory, T4 GC patients are prone to suffering peritoneal seeding. However, there are few studies exploring the recurrence patterns for T4 GC after curative resection.

In the present study, we aimed to clarify the prognostic factors and recurrence patterns for T4 GC after curative resection, which would help clinicians perform the appropriate treatment in order to improve survival.

\section{Methods and patients}

Between January 2004 and December 2014, a total of 249 gastric cancer patients were treated with curative resection ( $\mathrm{R} 0$ resection) and diagnosed as pathological T4 stage in Sun Yat-sen University Cancer Center. Standardized D2 lymphadenectomy or expanded resections for gastric cancer (including D2 + lymphadenectomy, or D2 lymphadenectomy plus the resection of other adjacent organs) were performed in these patients with curative resection. Tumors were staged according to the seventh edition of the American Joint Committee on Cancer (AJCC) tumor-node-metastasis (TNM) staging system [9]. Patients were excluded if they received neoadjuvant treatment, were diagnosed as late-stage gastric cancer or underwent R1/2 (microscopically/macroscopically residual tumor) resection. According to NCCN Guidelines [10], our clinicians recommended that all the included patients received adjuvant chemotherapy. However, in clinical practice, whether or not they received adjuvant chemotherapy was determined by the will of the patients.

All patients were followed up every 3 months in the first 2 years, 6 months in the 3-5 years, and 12 months annually thereafter, the median follow-up time was 25.87 months (range, 0.3-137).

The following clinicopathological data were collected prospectively through a constructed database: gender, age, tumor size, weight loss, tumor location, type of gastrectomy, extent of lymphadenectomy, intraoperative blood loss, postoperative complications, histological type, harvested lymph nodes, $\mathrm{N}$ stage, Lauren type, lymphatic invasion, venous invasion, perineural invasion and adjuvant chemotherapy. OS time was calculated from the time of surgery to death or the last follow-up date. Recurrence patterns were diagnosed based on imaging examination, gastroscopy with biopsy, and/or cytological examination of ascites, or intraoperative findings in patients who underwent reoperation.

\section{Statistical analysis}

Statistical analysis was performed using SPSS 17.0 for Windows (SPSS Inc, Chicago, IL, USA). Categorical variables, presented as rate, were compared by the $x^{2}$ (Chi-square) test. Continuous data, expressed as the mean \pm standard deviation (SD), were compared by Student's t-test. Survival outcomes were analyzed using the Kaplan-Meier method and compared using the log-rank test. Factors that were considered as significant in the univariate analysis $(\mathrm{P}<0.05)$ were included in the multivariate analysis by Cox regression. HR with $95 \%$ confidence intervals (CIs) were presented. $\mathrm{P}<0.05$ was considered statistically significant.

\section{Results}

\section{Patient characteristics}

The clinicopathologic characteristics of 249 patients were summarized in Table 1 . There were 221 T4a and 28 T4b GC patients receiving curative resection, comprising 165 males and 84 females, with a mean age of 56.10 years (range, 21-82 years). Some 221 patients underwent standard D2 lymphadenectomy, while 28 patients had expanded resection. The postoperative morbidity rate was $6.0 \%$. A total of 184 patients $(73.9 \%)$ received adjuvant chemotherapy after surgery. As shown in Table 2, the main organs invaded with T4b were the pancreas and spleen.

\section{Survival}

The median follow-up duration was 25.87 months (range, 0.3-137.0 months). The OS rate of 249 patients was $92.5 \%$ at 1 year, $65.3 \%$ at 3 years and $46.8 \%$ at 5 years (Fig 1 ).

Our results showed that the MST for T4a gastric cancer was longer than that for $\mathrm{T} 4 \mathrm{~b}$ gastric cancer [59.47 (95\% CI: 32.64-86.30) months versus 25.90 (95\% CI: 12.32-39.48) months] (Fig. 2A). The MST difference was significant $(\mathrm{P}=0.034)$. In the univariate analysis, age $(P=0.007)$ (Fig. $2 B)$, weight loss $(P=0.013)$, tumor location $(\mathrm{P}<0.001)$ (Fig. 2C), extent of lymphadenectomy $(\mathrm{P}=0.034)$, intraoperative blood loss $(\mathrm{P}<0.001)$ (Fig. $2 \mathrm{D})$, postoperative complications 
$(P=0.038)$ and $N$ stage $(P=0.012)$ were significant predictors of OS (Table 3). Multivariate analysis revealed that age $(\mathrm{P}=0.006)$, tumor location $(\mathrm{P}<$ $0.001)$ and intraoperative blood loss $(\mathrm{P}=0.010)$ remained as independent prognostic factors for long-term survival (Table 3).

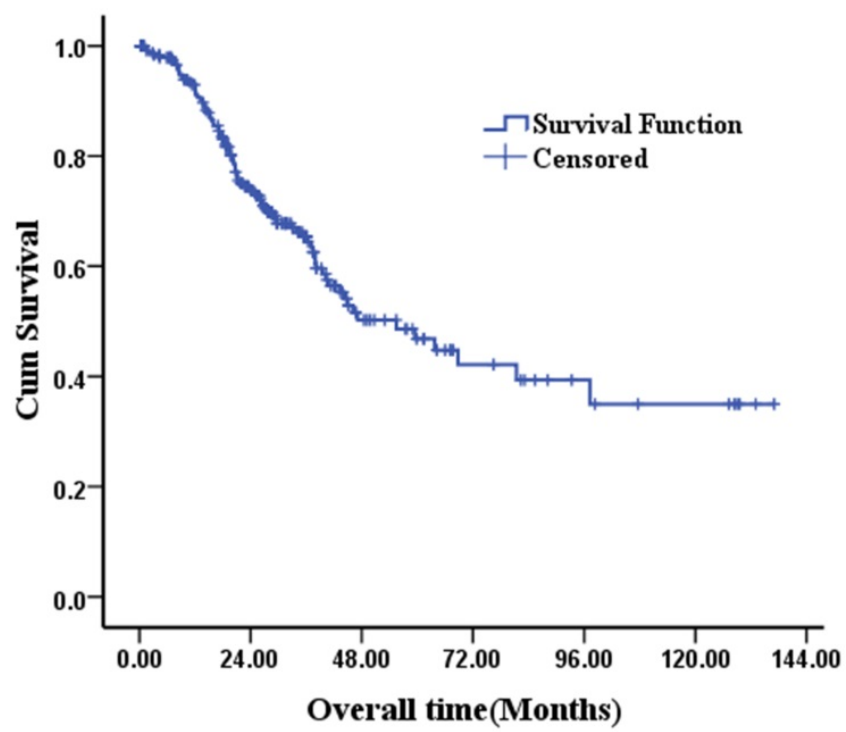

Fig. 1. Kaplan-Meier survival curves of 249 T4 gastric cancer patients after curative resection.

Table 1. Clinicopathologic characteristics for 249 patients with T4 gastric cancer after curative resection.

\begin{tabular}{ll}
\hline Variables & $\mathbf{n}(\%)$ \\
\hline Gender & \\
Male & $165(66.3)$ \\
Female & $84(33.7)$ \\
Age (y) & \\
$\leq 60$ & $156(62.7)$ \\
$>60$ & $93(37.3)$ \\
Tumor diameter (cm) & \\
$\leq 6.5$ & $176(70.7)$ \\
$>6.5$ & $73(29.3)$ \\
Weight loss (kg) & \\
$\leq 5$ & $197(79.1)$ \\
$>5$ & $52(20.9)$ \\
Location of tumor & \\
Upper 1/3 & $93(37.3)$ \\
Middle 1/3 & $38(15.3)$ \\
Lower 1/3 & $97(39.0)$ \\
Entire & $21(8.4)$ \\
Type of gastrectomy & \\
Distal & $103(41.4)$ \\
Proximal & $47(18.9)$ \\
Total & $99(39.7)$ \\
Lymphadenectomy & \\
D2 & $221(88.8)$ \\
Expanded D2 & $28(11.2)$ \\
Intraoperative blood loss (ml) & \\
>110 & $142(57.0)$ \\
Postoperative complications & $107(43.0)$ \\
Absence & \\
Presence & $234(94.0)$ \\
Histological type & $15(6.0)$ \\
Moderate or well differentiated & \\
Poorly differentiated & $26(10.4)$ \\
& $223(89.6)$ \\
\hline
\end{tabular}

\begin{tabular}{ll}
\hline $\begin{array}{l}\text { Number of harvested lymph nodes } \\
<15\end{array}$ & $21(8.4)$ \\
$\geq 15$ & $228(91.6)$ \\
N stage & \\
N0-N1 & $77(30.9)$ \\
N2-N3 & $172(69.1)$ \\
Lauren classification & \\
Intestinal & $99(39.8)$ \\
Diffuse & $25(10.0)$ \\
Mixed & $38(15.2)$ \\
Lymphatic invasion & \\
Absence & $138(55.4)$ \\
Presence & $111(44.6)$ \\
Venous invasion & \\
Absence & $151(60.6)$ \\
Presence & $98(39.4)$ \\
Perineural invasion & \\
Absence & $113(45.4)$ \\
Presence & $136(54.6)$ \\
Postoperative chemotherapy & \\
No & $65(26.1)$ \\
Yes & $184(73.9)$ \\
\hline
\end{tabular}

Table 2. Organs Invaded by T4b Gastric Cancer.

\begin{tabular}{lll}
\hline Invaded organs & $\mathbf{n}$ & $\mathbf{\%}$ \\
\hline Pancreas & 15 & 53.6 \\
Spleen & 13 & 46.4 \\
Liver & 4 & 14.3 \\
Transverse colon or & 3 & 10.7 \\
mesocolon & & \\
Adrenal gland & 2 & 7.2 \\
Gallbladder & 1 & 3.6 \\
Diaphragm & 1 & 3.6 \\
No. of invaded organs & & \\
One & 20 & 71.4 \\
Two & 6 & 21.4 \\
Four & 2 & 7.2 \\
\hline
\end{tabular}

\section{Pattern of recurrence and risk factors of recurrence}

After a median follow up of 25.87 months, a total of $109(43.8 \%)$ patients experienced recurrence. The recurrence rates for $\mathrm{T} 4 \mathrm{a}$ and $\mathrm{T} 4 \mathrm{~b}$ patients were $92 / 221$ $(41.6 \%)$ and $17 / 28(60.7 \%)$, respectively. Of these, the recurrence sites were obtained in a total of 90 patients, with a median of 15.90 (range: 1-71.1) months relapsing after curative surgery. The recurrence patterns were shown in Table 4. Among those 90 patients, peritoneal metastasis $(62.2 \%)$ was the most frequent recurrence site, followed by hematogenous metastasis $(26.7 \%)$, distant lymph node metastasis $(24.4 \%)$ and locoregional metastasis $(15.6 \%)$. The peritoneal metastasis was the most common recurrence pattern, accounting for $88.3 \%$ (10/12) recurrence in $\mathrm{T} 4 \mathrm{~b}$, and $59.0 \%(46 / 78)$ in T4a. The multivariate analysis showed that the $\mathrm{N}$ stage and intraoperative blood loss were the independent risk factors for recurrence (Table 5). 

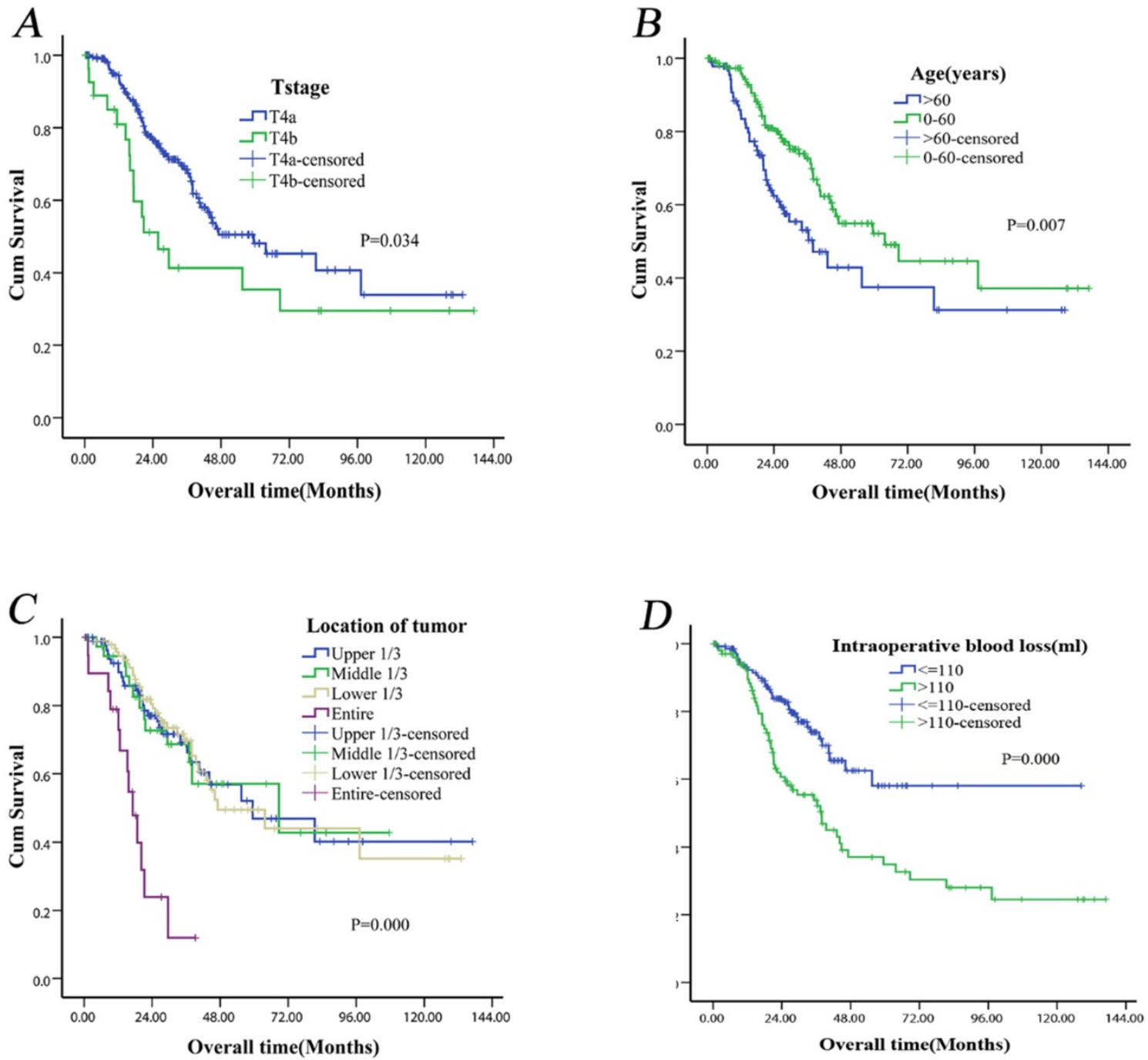

Fig. 2. Kaplan-Meier survival curves of T4 gastric cancer patients after curative resection according to tumor invasion $(T 4 a$ vs. T4b) $(P=0.034)(A)$, age $(P=0.007)(B)$, tumor location $(P<0.001)(C)$, intraoperative blood loss $(P<0.001)(D)$. All P-values were calculated using the log-rank test.

Table 3. Univariate analysis of risk factors and Multivariable Cox regression analysis of risk factors for patients with T4 gastric cancer.

\begin{tabular}{|c|c|c|c|c|}
\hline \multirow[t]{2}{*}{ Variables } & \multicolumn{2}{|l|}{ Univariate analysis } & \multicolumn{2}{|l|}{ Multivariate analysis } \\
\hline & Hazard ratio $(95 \% \mathrm{CI})$ & P value & Hazard ratio $(95 \% \mathrm{CI})$ & $P$ value \\
\hline Gender & & 0.555 & & \\
\hline Male & 1 & & & \\
\hline Female & $1.144(0.732 \sim 1.787)$ & & & \\
\hline Age $(y)$ & 1 & 0.007 & & 0.006 \\
\hline$\leq 60$ & $1.769(1.160 \sim 2.697)$ & & 1 & \\
\hline$>60$ & & & 1.859 (1.195 2.892) & \\
\hline Tumor diameter $(\mathrm{cm})$ & & 0.026 & & 0.561 \\
\hline$\leq 6.5$ & 1 & & 1 & \\
\hline$>6.5$ & $1.622(1.055 \sim 2.494)$ & & $0.844(0.477 \sim 1.494)$ & \\
\hline Weight loss $(\mathrm{kg})$ & & 0.013 & & 0.067 \\
\hline$\leq 5$ & 1 & & 1 & \\
\hline$>5$ & $1.785(1.120 \sim 2.844)$ & & $1.593(0.968 \sim 2.623)$ & \\
\hline Location of tumor & & 0.000 & & 0.000 \\
\hline Upper $1 / 3$ & 1 & & 1 & \\
\hline Middle $1 / 3$ & $1.016(0.526 \sim 1.963)$ & & $1.252(0.626 \sim 2.503)$ & \\
\hline Lower $1 / 3$ & $0.966(0.585 \sim 1.593)$ & & $0.899(0.537 \sim 1.506)$ & \\
\hline Entire & $4.854(2.463 \sim 9.567)$ & & $5.640(2.463 \sim 12.915)$ & \\
\hline Type of gastrectomy & & 0.204 & & \\
\hline Proximal & 1 & & & \\
\hline Distal & $1.195(0.682 \sim 2.094)$ & & & \\
\hline Total & $1.535(0.954 \sim 2.468)$ & & & \\
\hline Lymphadenectomy & & 0.034 & & 0.819 \\
\hline
\end{tabular}




\begin{tabular}{|c|c|c|c|c|}
\hline \multirow[t]{2}{*}{ Variables } & \multicolumn{2}{|l|}{ Univariate analysis } & \multicolumn{2}{|l|}{ Multivariate analysis } \\
\hline & Hazard ratio $(95 \% \mathrm{CI})$ & P value & Hazard ratio $(95 \% \mathrm{CI})$ & P value \\
\hline D2 & 1 & & 1 & \\
\hline Expanded D2 & $1.801(1.037 \sim 3.125)$ & & $1.072(0.588 \sim 1.955)$ & \\
\hline Intraoperative blood loss (ml) & & 0.000 & & 0.010 \\
\hline$\leq 110$ & 1 & & 1 & \\
\hline$>110$ & $2.148(1.392 \sim 3.316)$ & & $1.851(1.162 \sim 2.950)$ & \\
\hline Postoperative complications & & 0.038 & & 0.223 \\
\hline Absence & 1 & & 1 & \\
\hline Presence & $2.130(1.027 \sim 4.420)$ & & $1.606(0.750 \sim 3.439)$ & \\
\hline Histological type & & 0.913 & & \\
\hline $\begin{array}{l}\text { Moderate or well } \\
\text { differentiated }\end{array}$ & 1 & & & \\
\hline Poorly differentiated & $1.037(0.536 \sim 2.007)$ & & & \\
\hline Number of harvested lymph nodes & & 0.156 & & \\
\hline$\leq 15$ & 1 & & & \\
\hline$>15$ & $0.663(0.374 \sim 1.175)$ & & & \\
\hline $\mathrm{N}$ stage & & 0.012 & & 0.113 \\
\hline N0-N1 & 1 & & 1 & \\
\hline N2-N3 & $1.874(1.137 \sim 3.089)$ & & $1.520(0.906 \sim 2.551)$ & \\
\hline Lauren classification & & 0.849 & & \\
\hline Intestinal & 1 & & & \\
\hline Diffuse & $0.896(0.370 \sim 2.173)$ & & & \\
\hline Mixed & $0.790(0.344 \sim 1.816)$ & & & \\
\hline Lymphatic invasion & & 0.082 & & \\
\hline Absence & 1 & & & \\
\hline Presence & $1.458(0.951 \sim 2.235)$ & & & \\
\hline Venous invasion & & 0.923 & & \\
\hline Absence & 1 & & & \\
\hline Presence & $1.023(0.644 \sim 1.625)$ & & & \\
\hline Perineural invasion & & 0.549 & & \\
\hline Absence & 1 & & & \\
\hline Presence & $0.871(0.555 \sim 1.368)$ & & & \\
\hline Postoperative chemotherapy & & 0.272 & & \\
\hline No & 1 & & & \\
\hline Yes & $0.760(0.465 \sim 1.242)$ & & & \\
\hline T4 stage & & 0.034 & & \\
\hline $\mathrm{T} 4 \mathrm{a}$ & 1 & & & \\
\hline $\mathrm{T} 4 \mathrm{~b}$ & 1.801 (1.037 3.125) & & & \\
\hline
\end{tabular}

Table 4. Sites of recurrence in 90 patients.

\begin{tabular}{lllll}
\hline Recurrence site & Total group (\%) & T4a & T4b & P value \\
\hline peritoneum implanting & $56(62.2)$ & 46 & 10 & 0.105 \\
Hematogenous & $24(26.7)$ & 21 & 3 & 0.888 \\
distant lymph node & $22(24.4)$ & 20 & 2 & 0.501 \\
Locoregional & $14(15.6)$ & 14 & 0 & 0.110 \\
No. of sites & & & & \\
One & $67(74.4)$ & & & \\
Two & $19(21.1)$ & & & \\
Three & $4(4.5)$ & & & \\
\hline
\end{tabular}

\section{Discussion}

Even with the development of standardized D2 lymphadenectomy [2] and subsequent adjuvant chemotherapy $[4,11]$ for gastric cancer, the survival outcomes are still unsatisfactory, causing a third of cancer-related deaths worldwide [1]. Patients often suffer from recurrence after curative resection in the first 5 years, especially $\mathrm{T} 4$ patients. Better understanding of the prognostic factors and recurrence patterns for $\mathrm{T} 4$ gastric cancer will help clinicians to perform more intensive treatment strategies for high-risk patients. In the present study, our results demonstrated that age, tumor location and intraoperative blood loss were the prognostications of
OS for T4 gastric cancer after curative resection. Moreover, peritoneal metastasis was the most common pattern of recurrence.

Several studies $[6-8,12,13]$ had reported the prognostic factors for T4 gastric cancer. Fukuda et al [6] reported that number of metastatic lymph nodes, venous invasion and peritoneal washing cytology influenced the prognosis of $\mathrm{T} 4$ gastric cancer after potentially curative resection. Li et al [7] found that lymph node involvement was the only prognostic factor of OS. However, the sample sizes of previous studies were small, and they included patients with noncurative resection, such as $\mathrm{R} 1 / 2$ resection. While previous studies did not report the survival discrepancy regarding age, our results indicated that elderly patients (>60 years) had worse survival outcomes. The reasons for this might be considered as follows. First, disorder of immune function in elderly GC patients might relatively weaken antitumor capacity and lead to poor prognosis [14]. Second, compared to young patients, elderly patients cannot tolerate extensive lymphadenectomy and the toxicities of chemotherapy. Therefore, elderly patients get inadequate treatment, which affects survival. 
Table 5. Relationship between the recurrence and clinicopathologic characteristics by univariate and multivariable analysis in T4 gastric cancer patients after curative resection.

\begin{tabular}{|c|c|c|c|c|c|}
\hline \multirow[t]{2}{*}{ Variables } & \multicolumn{2}{|l|}{$\begin{array}{l}\text { Univariate } \\
\text { analysis }\end{array}$} & $X^{2}$ test & \multicolumn{2}{|l|}{$\begin{array}{l}\text { Multivariate } \\
\text { analysis }\end{array}$} \\
\hline & $\begin{array}{l}\text { No } \\
\text { recurrence }\end{array}$ & Recurrence & $\begin{array}{l}\mathrm{P} \\
\text { value }\end{array}$ & $\begin{array}{l}\text { Hazard ratio } \\
(95 \% \mathrm{CI})\end{array}$ & $\begin{array}{l}\mathrm{P} \\
\text { value }\end{array}$ \\
\hline No. of patients & $(n=140)$ & $(n=109)$ & & & \\
\hline Gender & & & 0.835 & & \\
\hline Male & 48 & 36 & & & \\
\hline Female & 92 & 73 & & & \\
\hline Age (y) & & & 0.385 & & \\
\hline$\leq 60$ & 91 & 65 & & & \\
\hline$>60$ & 49 & 44 & & & \\
\hline Tumor diameter $(\mathrm{cm})$ & & & 0.090 & & \\
\hline$\leq 6.5$ & 105 & 71 & & & \\
\hline$>6.5$ & 35 & 38 & & & \\
\hline Weight loss (kg) & & & 0.050 & & \\
\hline$\leq 5$ & 117 & 80 & & & \\
\hline$>5$ & 23 & 29 & & & \\
\hline Location of tumor & & & 0.115 & & \\
\hline Upper $1 / 3$ & 58 & 35 & & & \\
\hline Middle $1 / 3$ & 21 & 17 & & & \\
\hline Lower $1 / 3$ & 54 & 43 & & & \\
\hline Entire & 7 & 14 & & & \\
\hline Type of gastrectomy & & & 0.291 & & \\
\hline Proximal & 58 & 45 & & & \\
\hline Distal & 22 & 25 & & & \\
\hline Total & 60 & 39 & & & \\
\hline Lymphadenectomy & & & 0.055 & & \\
\hline D2 & 129 & 92 & & & \\
\hline Expanded D2 & 11 & 17 & & & \\
\hline $\begin{array}{l}\text { Intraoperative blood } \\
\text { loss (ml) }\end{array}$ & & & 0.004 & & 0.041 \\
\hline$\leq 110$ & 91 & 51 & & 1 & \\
\hline$>110$ & 49 & 58 & & $\begin{array}{l}1.778 \\
(1.024 \sim 3.088)\end{array}$ & \\
\hline $\begin{array}{l}\text { Postoperative } \\
\text { complications }\end{array}$ & & & 0.191 & & \\
\hline Absence & 134 & 100 & & & \\
\hline Presence & 6 & 9 & & & \\
\hline Histological type & & & 0.796 & & \\
\hline $\begin{array}{l}\text { Moderate or well } \\
\text { differentiated }\end{array}$ & 14 & 12 & & & \\
\hline Poorly differentiated & 126 & 97 & & & \\
\hline $\begin{array}{l}\text { Number of harvested } \\
\text { lymph nodes }\end{array}$ & & & 0.359 & & \\
\hline$\leq 15$ & 14 & 15 & & & \\
\hline$>15$ & 126 & 94 & & & \\
\hline $\mathrm{N}$ stage & & & 0.016 & & 0.019 \\
\hline N0-N1 & 52 & 25 & & 1 & \\
\hline N2-N3 & 88 & 84 & & $\begin{array}{l}1.992 \\
(1.119 \sim 3.545)\end{array}$ & \\
\hline Lauren classification & & & 0.308 & & \\
\hline Intestinal & 59 & 40 & & & \\
\hline Diffuse & 16 & 9 & & & \\
\hline Mixed & 28 & 10 & & & \\
\hline Lymphatic invasion & & & 0.879 & & \\
\hline Absence & 77 & 61 & & & \\
\hline Presence & 63 & 48 & & & \\
\hline Venous invasion & & & 0.308 & & \\
\hline Absence & 81 & 70 & & & \\
\hline Presence & 59 & 39 & & & \\
\hline Perineural invasion & & & 0.029 & & 0.139 \\
\hline Absence & 55 & 58 & & 1 & \\
\hline Presence & 85 & 51 & & $\begin{array}{l}0.659 \\
(0.379 \sim 1.145)\end{array}$ & \\
\hline $\begin{array}{l}\text { Postoperative } \\
\text { chemotherapy }\end{array}$ & & & 0.315 & & \\
\hline No & 40 & 25 & & & \\
\hline Yes & 100 & 84 & & & \\
\hline T4 stage & & & 0.055 & & \\
\hline $\mathrm{T} 4 \mathrm{a}$ & 128 & 92 & & & \\
\hline $\mathrm{T} 4 \mathrm{~b}$ & 11 & 17 & & & \\
\hline
\end{tabular}

The impact of intraoperative blood loss on long-term outcomes had been reported in various types of malignancy [15-18]. Dhar et al [19] reported that more than $500 \mathrm{ml}$ blood loss during surgery was an independent predictor of survival in gastric cancer patients with transmural depth invasion following a curative resection. Liang et al [20] also found intraoperative blood loss was an independent prognostic factor for gastric cancer after curative resection. In line with previous studies, our results showed that more intraoperative blood loss $(>110 \mathrm{ml})$ during surgery was an independent prognosis factor in T4 gastric cancer after curative resection. The exact mechanism of how blood loss affects the survival of patients remained unclear. It was considered that excessive intraoperative blood loss reduces the body's immunity, thus affecting the patients' ability to fight cancerous cells [19]. Therefore, our results implied that operating carefully to reduce intraoperative blood loss might improve the survival of T4 gastric cancer after curative resection.

In spite of improvements in surgical technique and adjuvant chemotherapy, advanced gastric cancer patients always suffered recurrence after curative resection. The majority of recurrences happened within 2 years postsurgery [21-25]. Previous studies had reported the recurrence patterns of gastric cancer [25-28], especially for patients with tumor invading serosa (T4 stage). However, the recurrence patterns of T4 gastric cancer with curative resection have not been reported. In the present study, 109 of 249 (43.8\%) patients experienced relapse. Among them, 90 patients had specifically documented recurrence sites, and peritoneal metastasis was the most frequent recurrence pattern $(n=56)$, accounting for $62.2 \%$ of all relapsed patients. For $\mathrm{T} 4 \mathrm{~b}$ patients, the peritoneal metastasis ratio reached $88.3 \%$. According to the seed and soil theory, when gastric cancer invades the serosa (T4), the cancer cells have a high possibility of falling into the peritoneal cavity where a suitable environment is provided for the cancer cells to grow. Kondo et al. reported that free cancerous cells could be found in $40 \%$ of stage II or III gastric cancers after peritoneal washings [29], suggesting that microscopic metastasis still remained after curative resection. Another study also reported that for advanced gastric cancer with serosal involvement, peritoneal metastasis usually occurred, with $15 \%-50 \%$ of patients having peritoneal metastasis at the time of surgery [30].

Peritoneal metastasis has been considered the terminal stage of gastric cancer, with a median overall survival of less than 6 months [31], accounting for almost $60 \%$ of all causes of GC death [32]. Therefore, understanding how to prevent and treat peritoneal 
metastasis is clinically important. In 1988, Fujimoto et al reported that hyperthermic intraperitoneal chemotherapy (HIPEC) was effective for gastric cancer patients with peritoneal seeding. A large number of studies also reported similar results [33-37]. Moreover, several prospective randomized controlled trials [38-41] also reported that curative resection with HIPEC was a useful treatment to prevent occurrence of peritoneal metastasis in advanced gastric cancer. Theoretically, HIPEC after curative resection could help eliminate free cancer cells and micro metastases in the abdominal cavity for T4 gastric cancer, which might prolong survival of patients. Nevertheless, this remained to be confirmed through well-designed randomized controlled trials.

There were several limitations in the present study. First, the present study was a retrospective, single-center research project. Second, the time span of this study was long (10 years). Therefore, the results of this study should be interpreted cautiously. A large-scale, validation study is required to confirm the results.

\section{Conclusions}

For T4 gastric cancer patients after curative resection, older age, entire gastric cancer and more intraoperative blood loss were associated with poor OS. The recurrence rate after curative resection for $\mathrm{T} 4$ was high, and the most common recurrence pattern was peritoneal metastasis.

\section{Competing Interests}

The authors have declared that no competing interest exists.

\section{References}

1. Torre LA, Bray F, Siegel RL ,et al. Global cancer statistics, 2012. CA Cancer J Clin, 2015; 65: 87-108.

2. Songun I, Putter H, Kranenbarg EM ,et al. Surgical treatment of gastric cancer: 15-year follow-up results of the randomised nationwide Dutch D1D2 trial. Lancet Oncol, 2010; 11: 439-449.

3. Sakuramoto $\mathrm{S}$, Sasako M, Yamaguchi $\mathrm{T}$,et al. Adjuvant Chemotherapy for Gastric Cancer with S-1, an Oral Fluoropyrimidine. N Engl J Med, 2007; 357: 1810-1820

4. Bang YJ, Kim YW, Yang HK, et al. Adjuvant capecitabine and oxaliplatin for gastric cancer after D2 gastrectomy (CLASSIC): a phase 3 open-label, randomised controlled trial. Lancet, 2012; 379: 315-321.

5. Neugut AI, Hayek M, Howe G. Epidemiology of gastric cancer. Seminars in Oncology, 1996; 23: 281-291.

6. Fukuda N, Sugiyama Y, Wada J. Prognostic factors of T4 gastric cancer patients undergoing potentially curative resection. World J Gastroenterol, 2011; 17: 1180-1184.

7. Li MZ, Deng L, Wang JJ et al. Surgical outcomes and prognostic factors of T4 gastric cancer patients without distant metastasis. PLoS One, 2014; 9: e107061.

8. Kunisaki C, Akiyama H, Nomura M, et al. Surgical outcomes in patients with T4 gastric carcinoma. J Am Coll Surg, 2006; 202: 223-230.

9. Washington K. 7th edition of the AJCC cancer staging manual: stomach. Ann Surg Oncol, 2010; 17: 3077-3079.

10. National Comprehensive Cancer Network N. NCCN Clinical Practice Guidelines in Oncology - Gastric Cancer - V.1.2016. National Comprehensive Cancer Network, Inc.; 2016.

11. Sasako M, Sakuramoto S, Katai $\mathrm{H}$,et al. Five-year outcomes of a randomized phase III trial comparing adjuvant chemotherapy with S-1 versus surgery alone in stage II or III gastric cancer. J Clin Oncol, 2011; 29: 4387-4393.
12. Kim JH, Jang YJ, Park SS ,et al. Surgical outcomes and prognostic factors for T4 gastric cancers. Asian J Surg, 2009; 32: 198-204.

13. Mita K, Ito H, Fukumoto $M$, et al. Surgical outcomes and survival after extended multiorgan resection for T4 gastric cancer. Am J Surg, 2012; 203: 107-111.

14. Sansoni $\mathrm{P}$, Cossarizza A, Brianti V ,et al. Lymphocyte Subsets and Natural Killer Cell Activity in Healthy Old People and Centenarians. Blood, 1993; 82: 2767-2773

15. Morner ME, Gunnarsson U, Jestin $\mathrm{P}$, et al. The importance of blood loss during colon cancer surgery for long-term survival: an epidemiological study based on a population based register. Ann Surg, 2012; 255: 1126-1128.

16. Mizuno A, Kanda M, Kobayashi D ,et al. Adverse Effects of Intraoperative Blood Loss on Long-Term Outcomes after Curative Gastrectomy of Patients with Stage II/III Gastric Cancer. Dig Surg, 2016; 33: 121-128.

17. Oefelein MG, Colangelo LA, Rademaker AW ,et al. Intraoperative blood loss and prognosis in prostate cancer patients undergoing radical retropubic prostatectomy. J Urol, 1995; 154: 442-447.

18. Nagai S, Fujii T, Kodera $Y$, et al. Impact of operative blood loss on survival in invasive ductal adenocarcinoma of the pancreas. Pancreas, 2011; 4: 3-9.

19. Dhar DK, Kubota $H$, Tachibana $M$, et al. Long-term survival of transmural advanced gastric carcinoma following curative resection: multivariate analysis of prognostic factors. World J Surg, 2000; 24: 588-593;

20. Liang YX, Guo HH, Deng JY, et al. Impact of intraoperative blood loss on survival after curative resection for gastric cancer. World J Gastroenterol, 2013; 19: 5542-5550

21. Shiraishi $\mathrm{N}$, Inomata $\mathrm{M}$, Osawa $\mathrm{N}$, et al. Early and late recurrence after gastrectomy for gastric carcinoma. Univariate and multivariate analyses. Cancer, 2000; 89: 255-261.

22. Chiang $\mathrm{CY}$, Huang $\mathrm{KH}$, Fang $\mathrm{WL}$, et al. Factors associated with recurrence within 2 years after curative surgery for gastric adenocarcinoma. World J Surg, 2011; 35: 2472-2478.

23. Sakar B, Karagol H, Gumus M, et al. Timing of Death From Tumor Recurrence After Curative Gastrectomy for Gastric Cancer. American Journal of Clinical Oncology, 2004; 27: 205-209.

24. Kang WM, Meng OB, Yu JC , et al. Factors associated with early recurrence after curative surgery for gastric cancer. World J Gastroenterol, 2015; 21: 5934-5940.

25. D'Angelica M, Gonen M, Brennan MF et al. Patterns of Initial Recurrence in Completely Resected Gastric Adenocarcinoma. Annals of Surgery, 2004; 240: 808-816.

26. Liu $\mathrm{D}, \mathrm{Lu} \mathrm{M}, \mathrm{Li} \mathrm{J}$,et al. The patterns and timing of recurrence after curative resection for gastric cancer in China. World J Surg Oncol, 2016; 14: 305.

27. Spolverato G, Ejaz A, Kim $Y$,et al. Rates and patterns of recurrence after curative intent resection for gastric cancer: a United States multi-institutional analysis. J Am Coll Surg, 2014; 219: 664-675.

28. Deng J, Liang H, Wang D ,et al. Investigation of the recurrence patterns of gastric cancer following a curative resection. Surg Today, 2011; 41: 210-215.

29. Juhl H, Stritzel M, Wroblewski A ,et al. Immunocytological detection of micrometastatic cells: comparative evaluation of findings in the peritoneal cavity and the bone marrow of gastric, colorectal and pancreatic cancer patients. Int J Cancer, 1994; 57: 330-335.

30. Sugarbaker PH, Yonemura Y. Clinical pathway for the management of resectable gastric cancer with peritoneal seeding: best palliation with a ray of hope for cure. Oncology, 2000; 58: 96-107.

31. Thomassen I, van Gestel YR, van Ramshorst B et al. Peritoneal carcinomatosis of gastric origin: a population-based study on incidence, survival and risk factors. Int J Cancer, 2014; 134: 622-628.

32. Yonemura $\mathrm{Y}$, Endou $\mathrm{Y}$, Shinbo $\mathrm{M}$, et al. Safety and efficacy of bidirectional chemotherapy for treatment of patients with peritoneal dissemination from gastric cancer: Selection for cytoreductive surgery. J Surg Oncol, 2009; 100: 311-316.

33. Glehen $\mathrm{O}$, Schreiber $\mathrm{V}$, Cotte $\mathrm{E}$, et al. Cytoreductive surgery and intraperitoneal chemohyperthermia for peritoneal carcinomatosis arising from gastric cancer. Arch Surg, 2004; 139: 20-26.

34. Yonemura $\mathrm{Y}$, Kawamura $\mathrm{T}$, Bandou $\mathrm{E}$, et al. Treatment of peritoneal dissemination from gastric cancer by peritonectomy and chemohyperthermic peritoneal perfusion. Br J Surg, 2005; 92: 370-375

35. Yang XJ, Li Y, Yonemura Y. Cytoreductive surgery plus hyperthermic intraperitoneal chemotherapy to treat gastric cancer with ascites and/or peritoneal carcinomatosis: Results from a Chinese center. J Surg Oncol, 2010; 101: 457-464.

36. Wu HT, Peng KW, Ji ZH , et al. Cytoreductive surgery plus hyperthermic intraperitoneal chemotherapy with lobaplatin and docetaxel to treat synchronous peritoneal carcinomatosis from gastric cancer: Results from a Chinese center. Eur J Surg Oncol, 2016; 42: 1024-1034.

37. Yang XJ, Huang CQ, Suo $\mathrm{T}$, et al. Cytoreductive surgery and hyperthermic intraperitoneal chemotherapy improves survival of patients with peritoneal carcinomatosis from gastric cancer: final results of a phase III randomized clinical trial. Ann Surg Oncol, 2011; 18: 1575-1581.

38. Fujimoto $\mathrm{S}$, Takahashi $\mathrm{M}$, Mutou $\mathrm{T}$, et al. Successful intraperitoneal hyperthermic chemoperfusion for the prevention of postoperative peritoneal recurrence in patients with advanced gastric carcinoma. Cancer, 1999; 85: 529-534. 
39. Zhu ZG, Tang R, Yan M ,et al. Efficacy and safety of intraoperative peritoneal hyperthermic chemotherapy for advanced gastric cancer patients with serosal invasion. A long-term follow-up study. Dig Surg, 2006; 23: 93-102.

40. Saladino E, Fleres F, Mazzeo C ,et al. The role of prophylactic hyperthermic intraperitoneal chemotherapy in the management of serosal involved gastric cancer. Anticancer Res, 2014; 34: 2019-2022.

41. Glehen O, Passot G, Villeneuve L et al. GASTRICHIP: D2 resection and hyperthermic intraperitoneal chemotherapy in locally advanced gastric carcinoma: a randomized and multicenter phase III study. BMC Cancer, 2014; 14: 183 